\title{
Anthropometric risk factors of cardiovascular disease in adult population of Dharan Municipality, Eastern Nepal: Gender and age differences
}

\author{
SHAH, S. ${ }^{1 *}$, KOIRALA, S. ${ }^{1}$, KHANAL, L. ${ }^{1}$ and KOIRALA, B. ${ }^{2}$ \\ ${ }^{1}$ Department of Human Anatomy, B.P. Koirala Institute of Health Sciences, Dharan-18, Koshi, Nepal \\ ${ }^{2}$ Department of Clinical Pharmacology \& Therapeutics, B.P. Koirala Institute of Health Sciences, \\ Dharan-18, Koshi, Nepal \\ *E-mail: San230dip@yahoo.com
}

\begin{abstract}
Introduction: Cardiovascular diseases (CVD) besides cancer are the most serious threat to the health and life of the population of both developed and developing countries. The aim of the study was to know the gender and age differences with anthropometric CVD risk factors among Nepalese adults of Dharan Municipality. Materials and Methods: A population based cross-sectional study was conducted using a pretested self-administered structured questionnaire on anthropometric parameters which can affect CVD. A systematic random sampling technique was applied to cover the estimated 280 households with 900 adult population. The parameters of anthropometric risk factors for cardiovascular diseases were Body Mass Index (BMI), Waist Hip Ratio (WHR) and Body Fat Percentage (BFP). The result was expressed as mean \pm SD. Independent student t test and ANOVA were applied to find out the gender and age differences respectively. "P" value of $<0.05$ was considered to indicate statistical significance. Results: The mean and SD of BMI, WHR and BFP were found to be $24.17 \pm 4.13,1.01 \pm 2.83$ and $26.91 \pm 7.15$ respectively. The gender differences of BFP were found to be statistically significant, whereas for BMI and WHR were not significant $(\mathrm{p}>0.05)$. The age differences in BMI and BFP were statistically significant $(<0.05)$ whereas for WHR was not found to be significant $(p>0.05)$. The significant positive correlations were found among these parameters $(\mathrm{p}<0.01)$. Conclusion:The results of this study emphasize the need for a comprehensive study (both lipid and anthropometric) for providing baseline data to prevent CVD in eastern Nepal.
\end{abstract}

Keywords: health, anthropometric, Nepal risk, factors.

\section{Introduction}

Cardiovascular diseases (CVD), among which the most common are hypertension, coronary heart disease and stroke, are a serious problem in modern medicine. They are, besides cancer, the most serious threat to the health and life of the population of both developed and developing countries. According to statistical data, cardiovascular mortality accounted for almost $48 \%$ of all deaths (BURKE and BELL, 2001).

At 2008, the prevalence of CVD in urban parts of India was estimated to be around $10 \%$ (six fold higher compared to 40 years ago), with 14.1 million affected in urban areas. The CVD burden afflicts both men and women, with deaths, accounting for $34 \%$ of all the deaths in women and $28 \%$ in men in 2007 (ROSAMOND, FLEGAL, FRIDAY et al., 2007) The Framingham Heart Study (FHS), carried out since 1948 in the USA for long-term observation and assessment of risk posed by cardiovascular disease in a representative group of 5209 men and women, introduced the term risk factor (KANNEL, 1976).

According to its definition, general cardiovascular risk is the probability of cardiovascular disease or death caused by it at a given time, which follows the synergistic activity of risk factors present in a given person. Various internal and external risk factors, often subject to modification, influence the incidence of cardiovascular disease. It has been possible to determine to what extent modification of these factors can affect the development of the disease (BOGGILD, KNUTSSON and SCAND, 1999. Currently, the so-called SCORE (Systematic Coronary Risk Evaluation) index developed by experts from eight European scientific societies is the basic tool for quick assessment of cardiovascular risk. It considers the following data: gender, age, cigarette smoking, systolic blood pressure and the level of total cholesterol (EUROPEJSKIE..., 2004) Many previous studies had suggested significant effects of anthropometric and physiological factors such as body weight, height, cholesterol, pulse rate, BMI, different skin folds, obesity, nutrition, smoking, oral contraceptive use, menopausal status, stress and physical activity on blood pressure (JACKSON, STEWART, BEAGLEHOLE et al., 1985; PAN, NANAS, DYER et al., 1986; MATTHEWS, COTTINGTON, TALBOTT et al., 1987; BADARUDDOZA SHARMA, BRAR and KUMAR, 2008).

Taking that into account, the present study focussed on the assessment of the anthropometric risk factors of cardiovascular disease in adult population of the Dharan municipality of Eastern Nepal.

The main objectives of the study were 
- To characterize adult population of three age categories (young adults, middle-aged adults and the elderly) of Eastern Nepal by anthropometric parameters such as Body fat percentage (BF), Basal metabolic Index (BMI) and Waist Hip ratio (WHR);

- To correlate the anthropometric risk factors with one another.

Based on our finding, we will intend to provide baseline evidence for health policy makers of Nepal about obesity and anthropometric risk factors of cardiovascular diseases that will allow them to raise awareness and preventive steps towards the lifestyle diseases in the entire country.

\section{Materials and Methods}

\subsection{Study design and setting}

A population based cross-sectional study was conducted using a pretested self-administered structured questionnaire on anthropometric parameters, which can affect CVD on adult populations of Dharan Municipality.

\subsection{Sample size estimation}

The sample size was calculated on the basis of prevalence (10\%) of CVD in reference to study conducted in urban parts of India, with a $20 \%$ allowable error $(95 \% \mathrm{CI})$ by using the following formula:

Sample size $(\mathrm{n})=4 \mathrm{pq} / \mathrm{L}^{2}$

Where, $\mathrm{p}=10 \%=0.1 \mathrm{q}=1-\mathrm{p}=1-0.1=0.9$

$\mathrm{L}=$ allowable error which is taken as $20 \%$ of $\mathrm{p}=0.2 \mathrm{X} 0.1=0.02$ Hence, Sample size $(\mathrm{n})=4 \mathrm{pq} / \mathrm{L}^{2}=4 \mathrm{X} 0.1 \mathrm{X} 0.9 /(0.02)^{2}=900$ individuals.

Thus, 900 adults were recruited for the study to identify the non-lipid anthropometric risk factors for cardiovascular diseases (BMI, WHR and BF). The study population included both sexes ( 450 males and 450 females) of three different age groups (300 individuals from each age group) of the Dharan municipality of Eastern Nepal. Participants were classified into three age groups: young adults (aged 18-35 years), middle aged adult (aged 36-59 years) and elderly aged group (aged $>60$ years). The cut off point for ages were the end of January so all participants must be of a certain age on lst February.

Considering the average family size of urban Nepal to be 5.0 , the minimum required households in the study were calculated as:

No. of individuals required/average family size $=900 / 5=180$

So a minimum of 180 households were required for the study. Further, as our sample size estimation, $1 \%$ of the total households of Dharan (280 households) were taken as a sample size in this study, which was more than $150 \%$ of above calculated value.

\subsection{Sampling technique}

A systematic random sampling technique was applied to cover the estimated 280 households. At first, a list of households in sequential order was prepared for each ward. Then for each ward, a house was chosen and rest households were identified by adding the constant (in our case 10). For example, to select 5 households out of 483 in ward 1, firstly house number 7 was picked up randomly and the rest of houses i.e. $17^{\text {th }}, 27^{\text {th }}$ were accordingly chosen.

\section{Inclusion Criteria}

- A residence of Dharan Municipality.

\section{Exclusion Criteria}

- Individuals disagreed to take part in the study.

\subsection{Consent}

Pre-informed written consents were obtained from each respondent and we also assured them about maintaining the anonymity during and after the study.

\subsection{Data collection}

For data collection personal interviews were held with each participant by the principal investigator. General information about name, address, sex, date of birth, education status and some lifestyle information were obtained. All the information obtained from as individuals were recorded on the predesigned proforma.

\subsection{Ethical clearance}

Ethical clearance of the study was taken from the Institutional ethical and the review board of BPKIHS. Participation in the study was voluntary and the purpose of the study was explained to participants prior to distribution of the questionnaires. Permission from the office of Dharan municipality and written consent were obtained from each study participant by attaching a statement of consent to each questionnaire.

\subsection{Measurements}

The anthropometric measurements taken were height $(\mathrm{cm})$, weight $(\mathrm{kg})$, waist circumference $(\mathrm{cm})$, hip circumference $(\mathrm{cm})$ and four site skin fold thickness ( $\mathrm{mm})$ - Biceps, Triceps, Subscapular and Suprailiac. Only non-lipid anthropometric CVD risk indicators were determined: BF, BMI, and WHR. All the anthropometric measurements were taken on each individual using standard anthropometric techniques (SINGH and BHASIN, 1968; WEINER and LOURIE, 1981). Height was measured barefoot in standing position to the nearest $0.5 \mathrm{~cm}$ using a secured metal ruler and weight was measured in light clothing using calibrated scales. BMI was calculated as a quotient of weight and squared height in meters $\left(\mathrm{kg} / \mathrm{m}^{2}\right)$. Waist circumference was measured at a level midway between the lower rib margin and the iliac crest to the nearest half-centimeter. Hip circumference was measured at the maximum protuberance of the buttocks. WHR was calculated as derived waist-to-hip circumference. Four sites skinfold thickness were measured by sliding vernier caliper and body fat percentage was calculated by Durnin/Womersley caliper method (LINEAR..., 2012). Biceps fold thickness (BFT); Triceps fold thickness (TFT); Subscapular fold thickness (SSFT) and Suprailaiac fold thickness (SIFT) were measured in $\mathrm{mm}$ to calculate Body Fat Percentage (BFP). 


\subsection{Statistical analysis}

The results were expressed as mean \pm SD. Independent student $t$ test and ANOVA were applied to find out the gender and age differences respectively. "P" value of $<0.05$ was considered to indicate statistical significance. Pearson's correlation coefficient ( $r$ ) was tested for association between anthropometric parameters. Statistical analyses were performed using the SPSS System software package 11.5.

\section{Results}

The mean age of all participants of the present study was found to be 24.17 years. The mean value of BMI, WHR and BFP were found to be $24.17 \mathrm{~kg} / \mathrm{m}^{2} ; 1.01$ and $26.91 \%$ respectively. (Table 1$)$. The BMI and BFP were found to be lower in males as compared with females $\left(24.14 \mathrm{~kg} / \mathrm{m}^{2} ; 22.54 \%\right.$ respectively $)$ but for WHR, was found to be higher in males (1.11). The gender difference in BMI and WHR were not found to be statistically significant ( $p>0.05$ ) but for BFP, $p$-value was found to be highly statistically significant $(<0.001)$ (Table 2$)$. The age difference in BMI and BFP were found to be highly statistically significant $(<0.001)$, whereas for WHR was not found to be statistically significant $(\mathrm{p}>0.05)$ (Table 3 ). The positive correlation was found between BMI, WHR and BFP in both sexes and all age groups. The correlation was significant $(<0.001)$ in both sexes (Table 4$)$.

Some life style questions were asked to the participants. In the present study, $9.4 \%$ of the participants were cigarette smoker; around $4 \%$ of participants were alcoholic; $88 \%$ of participants responded to have sleep hour equal or more than 7 ; around $12 \%$ of participants had sedentary lifestyle; $44.2 \%$ of participants had to travel during their works. Participants having Stress $>5$ (on 1-10 rating Scale) were around $12 \%$ (Table 5 ).

\section{Discussion}

In the present study, the gender differences of all measured parameters were found to be highly statistically significant $(\mathrm{p}<0.001)$ except for age, BMI and WHR (Table 2$)$. The age differences of all measured parameters were found to be statistically significant $(\mathrm{p}<0.001)$ except for WHR. The result of this study was found to be in agreement with the study done for Slovak inhabitants. BMI, BFP and WHR were positively correlated with all anthropometric risk factors (CHUDIKOVA, HAVELKOVA, MICHALOVIČOVA et al., 2005)

The study done in oravian population in Trnuva, found males having higher BMI and WHR (25.58 and 0.91 respectively) but in the present study, BMI in female was found to be higher (27.20). The BFP of the female population of the study was found slightly lower than the female study group of Zuzana (32.5\% and $31.28 \%$ respectively) (ZUZANA, 2012).

The 15-year prospective study conducted in 7000 men of age $40-59$ years showed that when BMI was greater than 26 , the risk of myocardial infarction, stroke and diabetes increased (WANNAMETHEE, SHAPER, LENNON et al., 2005). WHR is a better predictor for assessing the risk of development of CVD in females as compared with BMI (LEAN, HAN and MORRISON et al., 1995; VAN HORN, BALLEW, LIU et al., 1998). Men are characterized as having abdominal fat distribution (compared women having gluteofemoral body fat distribution) (DENNIS and GOLDBERG, 1993). CVD is considered to be more prominent in men (BISHNOI, KAUR and BADARUDDOZA, 2010) Particularly alarming is the systemic increase of obesity, especially among males, which may be connected to their low physical fitness, high rate of cigarette smoking and unhealthy diet. Worldwide studies, which had reported that anthropometric parameters were positively correlated with blood pressure (MOSCA, MCGILLEN and RUBENFIRE, 1998)

The limitations of the present study were lipid profile of the participants were not performed and other lifestyle risk factors associated with CVD were not assessed in detail.

Table 1. Mean and SD of all measured parameters.

\begin{tabular}{cc}
\hline Parameters & Mean \pm SD \\
\hline Age $($ Year $)$ & $45.24 \pm 19.32$ \\
Weight $(\mathrm{Kg})$ & $62.99 \pm 11.87$ \\
Height $(\mathrm{m})$ & $1.61 \pm 0.84$ \\
BMI $\left(\mathrm{Kg} / \mathrm{m}^{2}\right)$ & $24.17 \pm 4.14$ \\
WC $(\mathrm{cm})$ & $92.85 \pm 8.38$ \\
HC $(\mathrm{cm})$ & $90.75 \pm 8.94$ \\
WHR & $1.01 \pm 0.28$ \\
BFT $(\mathrm{mm})$ & $6.96 \pm 3.14$ \\
TFT $(\mathrm{mm})$ & $10.98 \pm 5.44$ \\
SSFT $(\mathrm{mm})$ & $13.80 \pm 5.22$ \\
SISFT $(\mathrm{mm})$ & $21.13 \pm 7.39$ \\
BFP $(\%)$ & $26.91 \pm 7.15$ \\
\hline
\end{tabular}

Table 2. Gender differences of all measured parameters.

\begin{tabular}{|c|c|c|c|}
\hline Parameters & Gender & Mean \pm SD & p-value \\
\hline \multirow[t]{2}{*}{ Weight (Kg) } & Male & $65.83 \pm 11.28$ & \\
\hline & Female & $60.15 \pm 11.78$ & $<0.001$ \\
\hline \multirow[t]{2}{*}{ Height (m) } & Male & $1.65 \pm 0.073$ & \\
\hline & Female & $1.58 \pm 0.077$ & $<0.001$ \\
\hline \multirow[t]{2}{*}{ BMI $\left(\mathrm{Kg} / \mathbf{m}^{2}\right)$} & Male & $24.14 \pm 3.98$ & \\
\hline & Female & $27.20 \pm 4.28$ & 0.844 \\
\hline \multirow[t]{2}{*}{ WC (cm) } & Male & $84.19 \pm 7.50$ & \\
\hline & Female & $81.52 \pm 8.98$ & $<0.001$ \\
\hline \multirow[t]{2}{*}{$\mathrm{HC}(\mathrm{cm})$} & Male & $91.62 \pm 9.17$ & \\
\hline & Female & $89.89 \pm 8.62$ & 0.004 \\
\hline \multirow[t]{2}{*}{ WHR } & Male & $1.11 \pm 0.04$ & \\
\hline & Female & $0.91 \pm 0.05$ & 0.29 \\
\hline \multirow[t]{2}{*}{ BFT (mm) } & Male & $6.40 \pm 3.14$ & \\
\hline & Female & $7.52 \pm 3.58$ & $<0.001$ \\
\hline \multirow[t]{2}{*}{ TFT (mm) } & Male & $10.28 \pm 6.14$ & \\
\hline & Female & $11.69 \pm 4.53$ & $<0.001$ \\
\hline \multirow[t]{2}{*}{ SSFT (mm) } & Male & $12.76 \pm 5.28$ & \\
\hline & Female & $14.84 \pm 4.95$ & $<0.001$ \\
\hline \multirow[t]{2}{*}{ SISFT (mm) } & Male & $20.33 \pm 7.72$ & \\
\hline & Female & $21.94 \pm 6.96$ & 0.001 \\
\hline \multirow[t]{2}{*}{ BFP (\%) } & Male & $22.54 \pm 5.97$ & \\
\hline & Female & $31.28 \pm 5.33$ & $<0.001$ \\
\hline \multirow[t]{2}{*}{ Age (year) } & Male & $45.64 \pm 19.69$ & \\
\hline & Female & $44.85 \pm 18.96$ & 0.54 \\
\hline
\end{tabular}


Table 3. Age differences of all measured parameters.

\begin{tabular}{ccccc}
\hline Parameters & $\begin{array}{c}\text { Young aged } \\
(\text { Mean } \pm \text { SD })\end{array}$ & $\begin{array}{c}\text { Middle aged } \\
(\text { Mean } \pm \text { SD })\end{array}$ & $\begin{array}{c}\text { Elderly aged } \\
(\text { Mean } \pm \text { SD })\end{array}$ & P value \\
\hline Age $($ year $)$ & $22.68 \pm 5.22$ & $45.60 \pm 6.70$ & $67.51 \pm 6.31$ & $<0.001$ \\
Weight $(\mathbf{K g})$ & $62.95 \pm 11.77$ & $63.59 \pm 12.85$ & $62.22 \pm 11.95$ & $<0.001$ \\
Height $(\mathbf{m})$ & $1.59 \pm 0.81$ & $1.53 \pm 0.70$ & $1.53 \pm 0.66$ & 0.001 \\
BMI $\left(\mathbf{K g} / \mathbf{m}^{2}\right)$ & $26.81 \pm 5.84$ & $27.09 \pm 6.36$ & $26.50 \pm 6.06$ & $<0.001$ \\
WC $(\mathbf{c m})$ & $79.00 \pm 7.61$ & $78.88 \pm 7.74$ & $79.30 \pm 7.37$ & $<0.001$ \\
HC $(\mathbf{c m})$ & $88.35 \pm 5.06$ & $87.89 \pm 5.70$ & $88.20 \pm 5.37$ & $<0.001$ \\
WHR & $0.89 \pm 0.05$ & $0.89 \pm 0.55$ & $0.89 \pm 0.04$ & 0.377 \\
BFT $(\mathbf{m m})$ & $10.70 \pm 3.32$ & $10.72 \pm 3.46$ & $10.47 \pm 3.50$ & $<0.001$ \\
TFT $(\mathbf{m m})$ & $13.57 \pm 3.79$ & $13.20 \pm 4.34$ & $12.80 \pm 4.45$ & 0.008 \\
SSFT $(\mathbf{m m})$ & $10.61 \pm 3.70$ & $10.82 \pm 3.10$ & $10.59 \pm 3.27$ & $<0.001$ \\
SISFT $(\mathbf{m m})$ & $9.59 \pm 2.70$ & $10.68 \pm 8.83$ & $10.72 \pm 1.05$ & $<0.001$ \\
BFP $(\%)$ & $32.95 . \pm 9.33$ & $32.99 \pm 9.49$ & $32.22 \pm 9.94$ & $<0.001$ \\
\hline
\end{tabular}

Table 4. Correlation coefficients of some variables (r).

\begin{tabular}{|c|c|c|c|c|c|}
\hline \multirow{2}{*}{ Parameters } & \multicolumn{2}{|c|}{ Gender } & \multicolumn{3}{|c|}{ Age } \\
\hline & Male & Female & Young & Middle & Elderly \\
\hline BFP & $\operatorname{BMI}\left(0.743^{* *}\right)$ & $\operatorname{BMI}\left(0.544^{* *}\right)$ & $\operatorname{BMI}\left(0.241^{* *}\right)$ & $\operatorname{BMI}\left(0.729^{* *}\right)$ & $\operatorname{BMI}\left(0.585^{* *}\right)$ \\
\hline WHR & $\operatorname{BMI}\left(0.102^{* *}\right)$ & $\operatorname{BMI}\left(0.200^{* *}\right)$ & $\operatorname{BMI}\left(0.157^{* *}\right)$ & $\mathrm{BMI}(0.052)$ & $\mathrm{BMI}(0.34)$ \\
\hline & $\operatorname{BFP}\left(0.126^{* *}\right)$ & $\operatorname{BFP}\left(0.113^{* *}\right)$ & $\operatorname{BFP}(0.178 * *)$ & $\operatorname{BFP}(0.035)$ & $\operatorname{BFP}(0.01)$ \\
\hline
\end{tabular}

**Correlation is significant $<0.001$ level $(2$-tailed).

Table 5. Some lifestyle related information from the participants.

\begin{tabular}{cc}
\hline Lifestyle related information & Response (\%) \\
\hline Cigarette Smoking & 9.4 \\
Alcoholic & 3.9 \\
Sleep hour equal or more than 7 & 87.8 \\
Sedentary lifestyle & 12.2 \\
Travelled during the job & 44.2 \\
Stress level $>5$ on the rating scale & 12.1 \\
History of both parents overweight & 12.3 \\
Childhood overweight & 7.8 \\
\hline
\end{tabular}

\section{Conclusion}

The results of this study emphasize the need for a comprehensive study (Lipid, lifestyle and anthropometric) for providing baseline data to prevent CVD in eastern Nepal.

\footnotetext{
Abbreviations

CVD: Cardiovascular diseases; FHS: Framingham Heart Study; SCORE: Systematic Coronary Risk Evaluation; BMI: Body Mass Index; WC: waist circumference; HC: hip circumference.

WHR: waist hip ratio; BFT: Biceps fold thickness; TFT: Triceps fold thickness; SSFT: Subscapular fold thickness; SIFT: Suprailiac fold thickness and BFP: Body Fat Percentage.

Acknowledgements: The authors would like to thank the B.P Koirala Institute of Health Sciences, Dharan, Nepal for allowing us to do this research project. We would like to thank the Office of Dharan Municipality and all the participants of the study for their cooperation during data collection and facilitation to conduct this study.
}

\section{References}

BADARUDDOZA SHARMA, M., BRAR, SK., and KUMAR, R. Age trends in morphophysiological traits among 19-24 years Punjabi female youth of Amritsar city in Punjab, India. The Anthropologist, 2008, vol. 10, p. 147-149.

BISHNOI, K., KAUR, T. and BADARUDDOZA. Predictor of cardiovascular disease with respect to BMI, WHR and lipid profile in females of three population groups. Biology and Medicine, 2010, vol. 2 , n. 2, p. 32-41.

BOGGILD, H., KNUTSSON, A. and SCAND, J. Shift work, risk factors and cardiovascular disease. Scandinavian Journal of Work, Environment e Health, 1999, vol. 25, n. 2, p. 85-99. PMid:10360463. http://dx.doi.org/10.5271/sjweh.410.

BURKE, GL. and BELL, RA.Trends in cardiovascular disease: incidence and risk factors. In: WONG, ND., BLACK, HR., GARDIN, JM. (Eds.). Preventive cardiology. New York: McGraw-Hill, 2000. p. 21-46.

CHUDIKOVA, K., HAVELKOVA, B., MICHALOVIČOVA, M. and ROVNY, I. The evaluation of nutrition status in Slovak inhabitants in the relationship with CVD risk. Cardiology, 2005, vol. 14, n. 1, p. 27-36.

DENNIS, KE. and GOLDBERG, AP. Differential effects of body fatness and body fat distribution on risk factors on cardiovascular disease in women. Arteriosclerosis and Thrombosis, 1993, vol. 13, p. 1487-1494. PMid:8399086. http://dx.doi.org/10.1161/01. ATV.13.10.1487.

EUROPEJSKIE TOWARZYSTWO KARDIOLOGICZNE. Europejskie wytyczne dotyczace prewencji chorób sercowo-naczyniowych w praktyce klinicznej. Kardiologia Polska, 2004, vol. 61, suppl I, p. 1-192.

JACKSON, R., STEWART, A., BEAGLEHOLE, R. and SERAGG, R. Alcohol consumption and blood pressure. American Journal of Epidemiology, 1985, vol. 122, n. 6, p. 1037-1044. PMid:4061438. http://dx.doi.org/10.1093/oxfordjournals.aje.al14185. 
KANNEL, WB. The Framingham study. British Medical Journal, 1976, vol. 2, n. 6046, p. 1255. PMid:990870. http://dx.doi.org/10.1136/ bmj.2.6046.1255-a.

LEAN, MEJ., HAN, TS., and MORRISON, CE. Waist circumference as a measure for indicating need for weight management. British Medical Journal, 1995, vol. 331, p. 158-161.

LINEAR SOFTWARE. Body fat calculator. 2012. Available from: <www.linear-software.com/online.html>. Access in: 5 Mar. 2015.

MATTHEWS, KA., COTTINGTON, EM., TALBOTT, E., KULLER, LH. and SIEGEL, JM. Stressful work conditions and diastolic blood pressure among blue-collar factory workers. American Journal of Epidemiology, 1987, vol. 126, n. 2, p. 280-291. PMid:3605056. http://dx.doi.org/10.1093/aje/126.2.280.

MOSCA, L., MCGILLEN, C. and RUBENFIRE, M. Gender differences in barriers to lifestyle change for cardiovascular disease prevention. Journal of Women's Health, 1998, vol. 7, n. 6, p. 712714. PMid:9718539. http://dx.doi.org/10.1089/jwh.1998.7.711.

PAN, WH., NANAS, S., DYER, A., LIV, K., MCDONALD, A., SCHOENBERGER, JA., SHEKELLE, RB., STAMLER, R. and STAMLER, J. The role of weight in the positive association between age and blood pressure. American Journal of Epidemiology, 1986, vol. 24 , p. 612-623.

ROSAMOND, W., FLEGAL, K., FRIDAY, G., FURIE, K., GO, A., GREENLUND, K., HAASE, N., HO, M., HOWARD, V., KISSELA, B., KITTNER, S., LLOYD-JONES, D., MCDERMOTT, M., MEIGS, J., MOY, C., NICHOL, G., O'DONNELL, CJ., ROGER, V., RUMSFELD, J., SORLIE, P., STEINBERGER, J., THOM, T.,
WASSERTHIEL-SMOLLER, S. and HONG, Y. Heart disease and stroke statistics update: a report from the American Heart Association Statistics Committee and Stroke Statistics Subcommittee. Circulation, 2007, vol. 115, no. 5, p. e69-el71. PMid:17194875. http://dx.doi. org/10.1161/CIRCULATIONAHA.106.179918.

SINGH, P. and BHASIN, MK. Anthropometry. Delhi: Kamla Raj Enterprises, 1968.

VAN HORN, LV., BALLEW, C., LIU, K., MCDONALD, A., HILNER, JE., BURKE, GL., SAVAGE, PJ., BRAGG, C., CAAN, B., JACOBS JUNIOR, D. SLATTERY, M. and SIDNEY, S. Diet, body size, and plasma lipidslipoproteins in young adults: differences by race and sex. American Journal of Epidemiology, 1998, vol. 133, n. 1, p. 9-23. PMid:1983903. http://dx.doi.org/10.1093/oxfordjournals. aje.al15807.

WANNAMETHEE, SG., SHAPER, AG., LENNON, L. and MORRIS, RW. Metabolic syndrome vs Framingham Risk Score for prediction of coronary heart disease, stroke and type 2 diabetes mellitus. Archives of Internal Medicine, 2005, vol. 165, n. 22, p. 2644-2650. PMid:16344423. http://dx.doi.org/10.1001/archinte.165.22.2644.

WEINER, JS. and LOURIE, JA. Practical human biology. London: Academic Press, 1981.

ZUZANA, H. Some anthropometric risk factors of cardiovascular disease in Oravian adults (Central Slovakia): gender and age differences. Journal of Behavioral Health, 2012, vol. 1, n. 4, p. 294-301.

Received January 3, 2017 Accepted November 2, 2017 